THE KURUME MEDICAL JOURNAL

Vol.26, No.2, p.103-106, 1979

\title{
LEIOMYOSARCOMA IN THE SUPERFICIAL SOFT TISSUE OF THIGH
}

\section{- A CASE REPORT -}

\author{
TAKANORI CHO AND AKIRA TANIMURA \\ Second Department of Pathology, Kurume University School of Medicine, \\ Kurume, 830, Japan
}

Received for publication June 4, 1979

\begin{abstract}
A case of 44-year-old female who had a leiomyosarcoma in the superficial soft tissue of right thigh was presented.

After 2 months of tumor resection, she had metastatic foci in both lungs. The tumor, $16 \times 12 \times 10 \mathrm{~cm}$, was relatively well encapsulated and was located in the subcutaneous soft tissue. Microscopic finding showed spindle cells and polygonal cells in interlacing bundle. Mitosis had 13 in 50 high power fields and this tumor was diagnosed of malignancy.
\end{abstract}

\section{INTRODUCTION}

Leiomyosarcoma is well known as the tumor developing from uterus, alimentary tube, retroperitonium and other sites. However, occurrence of this tumor in the superficial soft tissue is relatively rare. Frequently myogenic tumor is very difficult to be evaluated its malignancy.

We are presenting here a case of leiomyosarcoma in the superficial soft tissue of thigh.

\section{CASE REPORT}

\section{1) Clinical data}

A 44-year-old female was referred to a private doctor in 1972 for further therapy of rheumatic arthritis. In Oct. 1973, she noticed the tumor mass in flexor surface of left thigh and had progressive thigh swelling. In Dec. 1974, she had a large tender mass which extended into left thigh. She had admitted to Almeida Hospital for the diagnosis of malignant tumor.

Physical examination showed a medium nourished woman with marked swelling and tenderness on the upper aspect of the left thigh. Movement of the left thigh caused pain. The temparature, pulse, respirations and blood pressure were normal. Examination of the blood revealed hemoglobin $12.9 \mathrm{~g} / \mathrm{dl}$, and white blood cell count 7,700. The total protein was $7.4 \mathrm{~g} / \mathrm{dl}$ (Al $39.3 \%$, $\alpha_{1}$-Gl $4.9 \%, \alpha_{2}$-Gl $11.5 \%, \beta$-Gl $10.2 \%$, $\gamma$-Gl $34.1 \%$ ), calcium $9.8 \mathrm{mg} / \mathrm{dl}, \mathrm{Na} 135$ $\mathrm{mEq} / \mathrm{L}, \quad \mathrm{K} \quad 4.2 \mathrm{mEq} / \mathrm{L}, \quad$ Cl $100.3 \mathrm{mEq} / \mathrm{L}$, and ALP was 2.0 units. Liver function was normal. X-ray film of the left femur showed normal structure.

On the 25th hospital day, the tumor mass was removed operatively. The tumor revealed no adhesion to adjacent skeletal muscles and covering dermis. It relatively well circumscribed and seemed to be originated from subcutaneous tissue.

2) Resected specimen (Fig. 1, 2)

The tumor consisted of relative soft, round mass measuring $16 \times 12 \times 10 \mathrm{~cm}$ and was covered by fibrous capsule. On cut section, it was revealed a whitish-gray coloured, firm to soft necrotic areas with hemorrhage and cyst formation. 


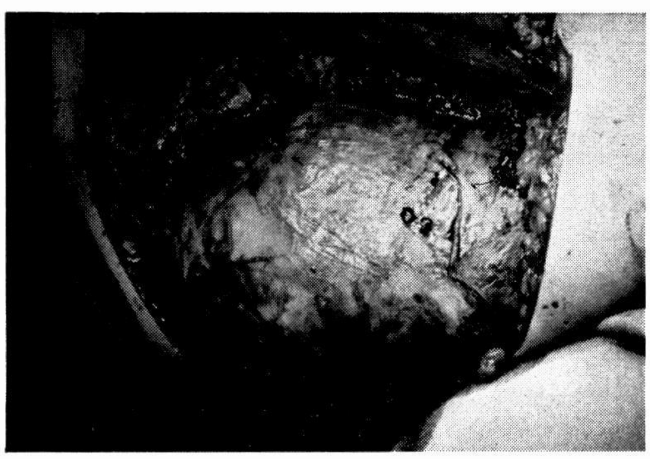

Fig. 1. Tumor mass was located in subcutaneous tissue.

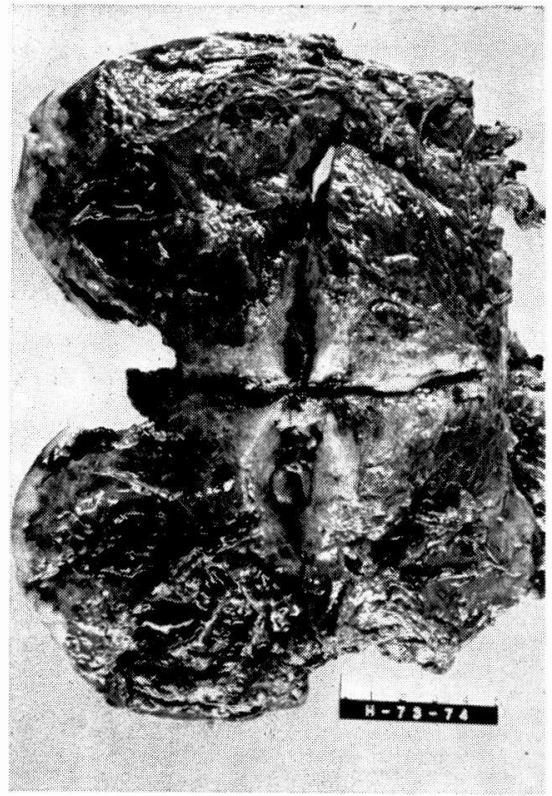

Fig. 2. Cut section of resected tumor shows a whitish-gray colored, firm to soft necrotic areas with hemorrhage.

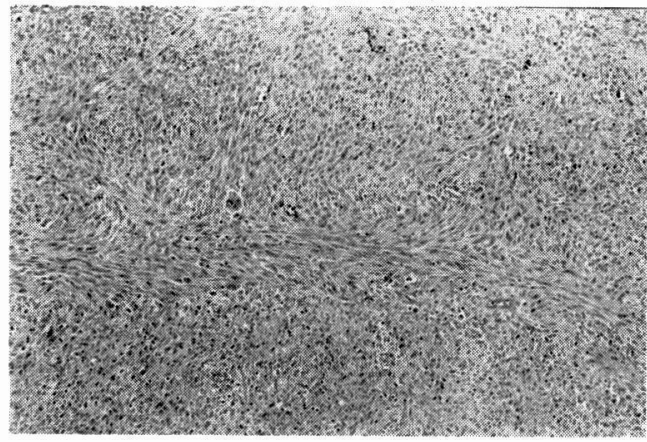

Fig. 3. Tumor tissue compose of interlaced spindle cells.

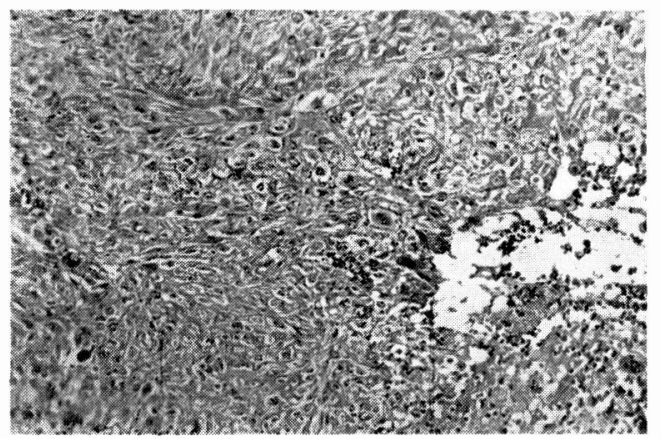

Fig. 4. Tumor cells surrounding necrobiotic area show round cell pattern.

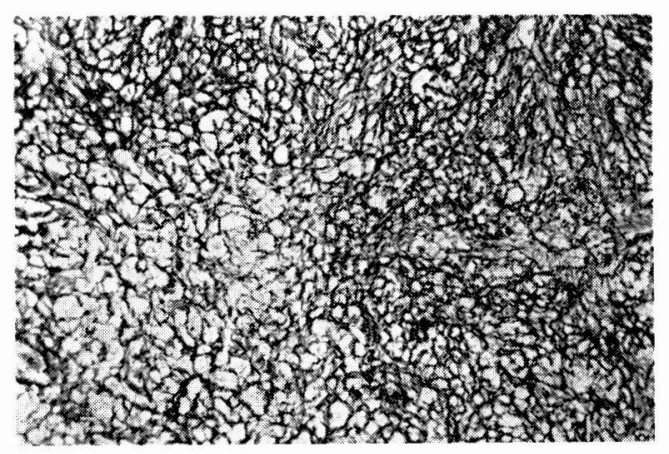

Fig. 5. Reticulin fibers surround the some tumor cells in box appearance. 


\section{3) Microscopic examination (Fig. 3, 4, 5)}

Tumor tissue mostly composed of irregular arranged, interlaced spindle cells and polygonal cells, however, tumor cells surrounding the necrobiotic area showed bizarre giant cell formation. The cells were variable in size and had eosinophilic cytoplasms with blunt ended nuclei and prominent nucleoli.

The nuclei often showed marked tendency to be aligned in palisade formation. Pleomorphic and giant cells were seen in the specimen that was taken near the necrobiotic area. There were 13 mitoses in 50 high power fields (200 $x)$. Tumor cells showed obvious intracellular myofibrils in the cytoplasm but did not in polygonal cells in PTAH stain. They were stained yellow in VanGieson stain and red in Azan stain suggesting to be myogenic nature. Reticulin stain showed that many fine fibers tended to be parallel to the long axis of the cells. The pathological diagnosis of resected specimen was leiomyosarcoma.

\section{4) Clinical course after operation}

After 2 months of operation, metastatic foci were found in both lungs.

Her condition slowly worsened despite irradiation therapy and chemotherapy. After about 9 months of operation, she died of cachectic status. Autopsy was not performed.

\section{DISCUSSION}

This case was leiomyosarcoma arisen from subcutaneous soft tissue and after 9 months of operation she died of pulmonary metastasis.

In general, leiomyosarcoma of superficial soft tissue is not frequent. In 1958, Stout and Hill reported 36 cases of leiomyosarcoma in superficial soft tissue. For clinical pathologist, most important matter is the differential diagnosis of benign or malignant except for existence of metastasis.

In size, $60 \%$ of leiomyosarcoma is more than $5.0 \mathrm{~cm}$ in diameter and mostly greater than $2.5 \mathrm{~cm}$, but in contrast with leiomyosarcoma, leiomyoma are mostly less than $1.0 \mathrm{~cm}$ in diameter. Grossly leiomyoma is always circumscribed and often encapsulated, but leiomyosarcoma has usually no apparent capsule unlike this case. It has the tendency to extend deeply and involve underlying muscles or fasciae.

Microscopical differentiation of these myogenic tumors (leiomyoma and leiomyosarcoma) is not easy. Leiomyosarcoma has generally various microscopic figures (anaplasia, giant cell formation, pleomorphism etc.). However, Spiro and McPeak (1966) reported two cases of metastasis from histologically benign uterine leiomyomata and the limitation of histologic criteria in assessing the potentially malignant of SM neoplasms was emphasized. Stout and Hill (1958) emphasized the number of mitosis as an important criteria of malignancy. If there is no mitotic figure in 50 or more high power fields $(200 \times)$, leiomyosarcoma is negative. On the other hand, if mitosis can be found at an average rate of 1 or more in every 5 high power fields, the tumor is almost certainly malignant and if the mitosis is as frequent as or more in every high power field, the tumor is certainly malignant. Sano (1963) and Ota (1957) in Japan also emphasized the frequency of mitosis. In our case, mitosis was found one or more in every high power field and corresponded with malignancy.

Leiomyosarcoma are often difficult to be distinguished from other malignant tumors. Some of the leiomyosarcoma could not always demonstrate the myofibril and could not easily diagnose as leiomyosarcoma except for detection of myofibrils. This case showed appar- 
ent myofibrils in spindle cells, but not in polygonal cells. Pleomorphic leiomyosarcoma does not always show easily recognized myofibrils. In such a case, silver impregnation method is useful as "box appearance" in transversal sections or "Sudare pattern" in longitudinal sections. In this case "box appearance" was found also by silver impregnation staining.

\section{ACKNOWLEDGMENTS}

We gratefully acknowledge the help and advice of Prof. Teruyuki Nakashima.

\section{REFERENCES}

OtA, K. and SAKamoto, S. (1957). Leiomyosarcoma of the intestine. Jap. J. Cancer Clin, 3, 521-531.

SANo, R. (1963). Two cases of superficial leiomyosarcoma. Med. Progr., 45, 36-38.

SpIRo, R.H. and McPeaK, C.J. (1966). On the so-called metastasizing leiomyoma. Cancer, 19, 544-548.

Stout, A. P. and Hill, W.T. (1958). Leiomyosarcoma of the superficial soft tissues. Cancer, 11, 844-854. 